\title{
Morphology and Antibacterial Properties of Copper Precipitates in Ferrite Stainless Steel
}

\author{
Hongxiang Yin, Yi Wu, Xiang Li, Guanzhen Zhang, Pengpai Zhang, Wenbo Li, and Aimin Zhao
}

Submitted: 29 August 2020 / Revised: 13 November 2020 / Accepted: 14 November 2020 / Published online: 4 January 2021

\begin{abstract}
The size of copper precipitates is the main factor affecting the antibacterial performance of antibacterial stainless steel. To study the mechanism of copper precipitate growth in ferritic stainless steel, the shape coefficient $\eta$ and average specific interfacial energy of copper precipitate $\bar{\sigma}$ were calculated. The growth process of copper precipitate was observed by atomic probe tomography and transmission electron microscope. The results show that the shape coefficient of copper precipitate was 3.053, and the average specific interfacial energy was $\bar{\sigma}=0.4832-0.1652 \times 10^{-3} \mathrm{~T}$. The increase in the aging time resulted in an increase in the size of copper precipitates and a decrease in the number density. In addition, with the increase in the aspect ratio, the shape of the precipitated phase changed from an initial spherical shape to ellipsoid shape and finally to a rod shape. The increase in the annealing time enhanced the antibacterial activity of the tested steel until almost $100 \%$ of the bacteria were killed. Thus, the antibacterial performance is closely related to the size and total surface area per unit area of the precipitate.
\end{abstract}

Keywords antibacterial properties, copper precipitate, precipitate growth, ultrapure ferritic stainless steel

\section{Introduction}

Public health events caused by pathogens, such as SARS, MERS, H1N1 and Ebola viruses, occur from time to time. For example, the COVID-19 pandemic has caused public panic worldwide since the beginning of 2020. Direct contact is one of the main transmission routes of infection by the virus. Therefore, using antibacterial materials to manufacture frequently used tools is important for reducing virus transmission. Ferritic antibacterial stainless steel are antibacterial functional structural materials. It is widely used in household appliances, kitchenware, sanitary ware and other metal antibacterial products (Ref 1-6). The analysis of antibacterial properties of copper-bearing steel is based on the copper precipitation in steel.

The kinetics of $\mathrm{Cu}$-rich phase are the theoretical basis for the study of copper precipitate behavior. For example, this was studied in $0.01 \mathrm{C}-2.01 \mathrm{Cu}$ steel $(\operatorname{Ref} 7)$, in which the activation energy values for the nucleation and growth of $\mathrm{Cu}$-rich precipitates in $\mathrm{Cu}$ steel were $97.3 \mathrm{~kJ} / \mathrm{mol}$ and $182.6 \mathrm{~kJ} / \mathrm{mol}$ in $0.01 \mathrm{C}-2.01 \mathrm{Cu}$ steel, respectively. In addition, chemical composition and size of the precipitates are important to understand copper precipitate behavior. Goodman (Ref 8) reported that the precipitated particle consisted of approximately 50\% copper at the early stage of annealing, and the minimum size of

Hongxiang Yin, Yi Wu, Xiang Li, Guanzhen Zhang, Pengpai Zhang, and Wenbo Li, Metal and Chemistry Research Institute, China Academy of Railway Sciences Corporation Limited, Beijing 100081, China; and Aimin Zhao, Collaborative Innovation Center of Steel Technology, University of Science and Technology Beijing, Beijing 100083, China. Contact e-mail: icskyby@163.com.

precipitated particles was less than $1 \mathrm{~nm}$. Schwich (Ref 9) reported that nanometer-sized $\mathrm{Cu}$-rich precipitates had radius of 2.2 and $2.4 \mathrm{~nm}$ after aging at $600{ }^{\circ} \mathrm{C}$ for $120 \mathrm{~s}$ and $720 \mathrm{~s}$, respectively. At a longer aging time of $7200 \mathrm{~s}$, the pure $\mathrm{Cu}$ precipitate exhibited coarsening. The structure of copper precipitates in steel has been studied in detail. Othen (Ref 10) investigated the structural changes in the copper precipitates with the growth in the particle size during isothermal annealing of $\mathrm{Fe}-\mathrm{Cu}$ and $\mathrm{Fe}-\mathrm{Cu}-\mathrm{Ni}$ alloys. The results showed that the precipitation order of copper precipitate is as follows: bodycentered cubic (BCC) $\mathrm{Cu}$ clusters followed by $9 \mathrm{R}-\mathrm{Cu}, 3 \mathrm{R}-\mathrm{Cu}$ and face-centered cubic (FCC) $\mathrm{Cu}$ precipitate. Thus, the precipitates behavior varies greatly in different steels.

The antibacterial properties of copper-bearing steel have also been studied. Zhang (Ref 11) studied the effect of annealing temperature on the antibacterial properties of the copper-bearing stainless steel. The results show that the annealing process was conducted at $700-800{ }^{\circ} \mathrm{C}$, the precipitation of the antibacterial phase increased and the antibacterial properties were enhanced. Chen (Ref 12) studied the effect of annealing process on the antibacterial properties of stainless steel. The temperature of the solution treatment process conducted before the antibacterial annealing was found to have a significant effect on the copper precipitation behavior and antibacterial activity. Lin (Ref 13) has studied the effect of the $\mathrm{Cu}$ content on the antibacterial rate of ferritic stainless steel. When the copper content exceeded a certain level (approximately $1.2 \%$ ), good antibacterial performance was obtained. The antibacterial function can be attributed to the presence of $\mathrm{Cu}^{2+}$, which can kill Escherichia coli and Staphylococcus aureus (Ref 14, 15). Thus, $\mathrm{Cu}$ solid solution into a matrix cannot provide the antibacterial function unless copper is precipitated and grown to a certain size (Ref 16, 17).

In this study, a new type of ferritic stainless steel containing copper was designed. The composition of the test steel was innovative, and good comprehensive properties were obtained. It has very low carbon and nitrogen content $(\mathrm{Wt}(\mathrm{C}+\mathrm{N}) \leq$ $150 \mathrm{ppm}$ ) and high chromium content (Wt $(\mathrm{Cr}) \approx 21 \%$ ). Thus, the designed steel has good formability, corrosion 
resistance and antibacterial properties. The precipitation behavior of this type of steel has not been reported. Therefore, the effect of annealing time on the morphology, size and distribution of copper precipitate in high-copper (approximately 1.5\%) ultrapure ferritic stainless steel was studied in this paper. In addition, the antibacterial properties and mechanism of the designed steel were also discussed. The explanation of antibacterial mechanism of test steel in this paper is also a theoretical attempt.

\section{Experimental Materials and Methods}

Table 1 shows the composition of the tested steel, which was smelted in a $25 \mathrm{~kg}$ vacuum medium frequency induction furnace. The content of carbon plus nitrogen was less than $150 \times 10^{-6}$, while that of copper was $1.52 \%$. In order to obtain ultralow carbon and nitrogen content in the steel, industrial pure iron (99.6-99.8\%), pure silicon ( $\geq 99.9 \%$ ), pure manganese ( $\geq 99.9 \%$ ), pure niobium ( $\geq 99.9 \%$ ), titanium sponge ( $\geq 99.9 \%$ ), pure chromium ( $\geq 99.9 \%$ ), pure nickel ( $\geq 99.9 \%$ ) and pure copper ( $\geq 99.9 \%$ ) were used to smelt the test steel. The test steel was melted at $1650{ }^{\circ} \mathrm{C}$ for two hours and then tapping, and the pouring temperature was $1620^{\circ} \mathrm{C}$.

After peeling, the ingot was heated to $1100{ }^{\circ} \mathrm{C}$ for $2 \mathrm{~h}$ before starting the forging. The final forging temperature and size was $850{ }^{\circ} \mathrm{C}$ and $150 \mathrm{~mm} \times 150 \mathrm{~mm} \times 40 \mathrm{~mm}$, respectively. The forging was heated to $1250{ }^{\circ} \mathrm{C}$ for $2 \mathrm{~h}$ and then began to rolling. The ingot was rolled from 40 to $4 \mathrm{~mm}$ for 6 passes at an initial and final forging temperatures of 1100 and $900{ }^{\circ} \mathrm{C}$, respectively. The ingot was then cooled to $670{ }^{\circ} \mathrm{C}$ to simulate crimping.

Figure 1 shows the heat treatment process of the tested steel. After annealing at $980{ }^{\circ} \mathrm{C}$ for $3.5 \mathrm{~min}$, the hot-rolled plate was cold-rolled to $1.2 \mathrm{~mm}$. The samples were cut by wire cutting and annealed on a continuous annealing simulator. The sample was heated to $970{ }^{\circ} \mathrm{C}$ at a rate of $20{ }^{\circ} \mathrm{C} / \mathrm{s}$, solution-treated for $5 \mathrm{~min}$ and air-cooled to room temperature at $20^{\circ} \mathrm{C} / \mathrm{s}$. Nine samples were reheated to $800{ }^{\circ} \mathrm{C}$ for $10,30,60,180,600$, $2400,3600,21,600$ and $36,000 \mathrm{~s}$. They were then cooled to room temperature. Finally, the samples were cut by wire cutting and analyzed by atomic probe tomography (APT) and transmission electron microscope (TEM).

The analysis of APT was conducted on the LEAP3000HR ${ }^{\mathrm{TM}}$ equipment. The maximum field of view of the equipment is $150 \mathrm{~nm}$, and the spatial resolutions are $0.2 \mathrm{~nm}$ and $0.1 \mathrm{~nm}$ in the transverse and depth directions, respectively. The initial sample size was $0.5 \mathrm{~mm} \times 0.5 \mathrm{~mm} \times 20 \mathrm{~mm}$ made by wire cutting. Electropolishing was then used to shape the sample into a needlelike shape with a radius of less than $100 \mathrm{~nm}$. After the test completion, the collected data were processed by IVAS 3.6.0 software package. The copper precipitate was observed by Tecnai G2 F30 S-TWIN field emission high-resolution
TEM, and the samples were prepared by the double spraythinning method.

The antibacterial properties were examined base on the JIS Z 2801:2012 standard. The antibacterial properties of the tested steel were evaluated by the film sticking method. Escherichia coli ATCC 25922 was selected. The sizes of the test sample and the film were $50 \mathrm{~mm} \times 50 \mathrm{~mm}$ and $40 \mathrm{~mm} \times 40 \mathrm{~mm}$, respectively.

The shape coefficient of the cylindrical precipitate is the ratio of its length to bottom diameter. In order to calculate the actual shape coefficient, 20 rod-shaped precipitates were selected to calculate the average length L. Twenty circular areas were selected to calculate the average diameter D. So the shape factor is calculated to be $\mathrm{L} / \mathrm{D}$.

\section{Test Results and Discussion}

\subsection{Precipitation Shape Coefficient and Specific Interfacial Energy}

The FCC copper precipitate was the second phase in ferritic stainless steel with a lattice constant of $0.3615 \mathrm{~nm}$. On the other hand, the lattice constants of ferrite and chromium were $0.2870 \mathrm{~nm}$ and $0.2910 \mathrm{~nm}$ (Ref 18). Therefore, the lattice constant of the copper precipitate was larger than that of the ferrite matrix in the stainless steel containing $\mathrm{Cr}$. At room temperature, the shear modulus of copper is $48.3 \mathrm{GPa}$, and that of $\alpha$-Fe is $80.65 \mathrm{GPa}$ (Ref 18). Therefore, the shear modulus of copper precipitates is much smaller than that in the ferrite matrix. According to the misfit dislocation theory (Ref 19), the interfacial misfit dislocation exists in the phase where the product (G.b) of the shear modulus, G, and the Burgers vector, $\mathrm{b}$, is low. The copper precipitate G.b is smaller than that of the ferrite, and hence, the misfit dislocations are located in the antibacterial copper phase.

Thus, the Kurdjumov-Sachs (K-S) relationship between the copper precipitate and the matrix has been confirmed (Ref 20):

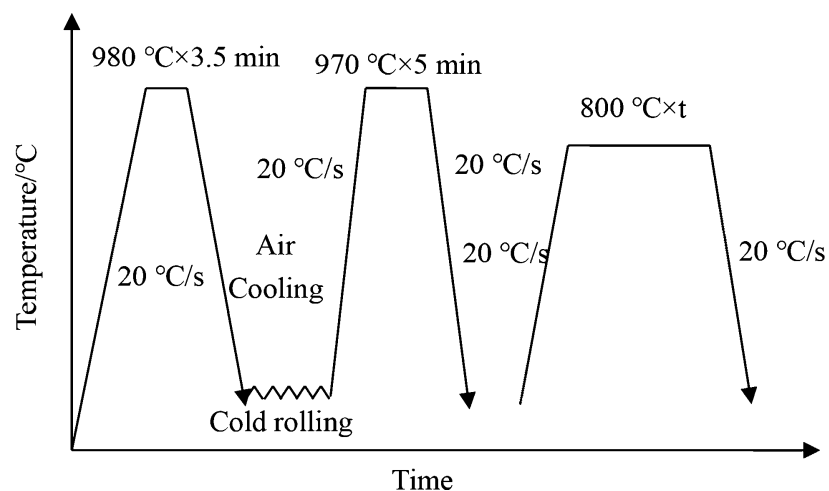

Fig. 1 Heat treatment process

Table 1 Chemical composition of the tested steel (mass fraction, \%)

\begin{tabular}{lcccccccccc}
\hline $\mathbf{C}$ & $\mathbf{S i}$ & $\mathbf{M n}$ & $\mathbf{N b}$ & $\mathbf{T i}$ & $\mathbf{C r}$ & $\mathbf{N i}$ & $\mathbf{C u}$ & $\mathbf{N}$ & $\mathbf{P}$ & $\mathbf{S}$ \\
\hline 0.0060 & 0.49 & 0.10 & 0.16 & 0.13 & 21.2 & 0.31 & 1.52 & 0.0055 & 0.016 & 0.006 \\
\hline
\end{tabular}




$$
\begin{aligned}
& (11 \overline{1})_{\varepsilon-\mathrm{Cu}} / /(\overline{1} 10)_{\alpha-\mathrm{Fe}} \\
& {[1 \overline{1} 0]_{\varepsilon-\mathrm{Cu}} / /[111]_{\alpha-\mathrm{Fe}}}
\end{aligned}
$$

The degree of mismatch in the $[11 \overline{1}]_{\varepsilon-\mathrm{Cu}} / /[\overline{1} 10]_{\alpha-\mathrm{Fe}}$ direction should be:

$\delta_{1}=\left|\frac{\sqrt{3} a_{\mathrm{Cu}}-2 \sqrt{2} a_{\alpha-\mathrm{Fe}}}{2 \sqrt{2} a_{\alpha-\mathrm{Fe}}}\right|=0.2290$

The degree of mismatch in the $[1 \overline{10}]_{\varepsilon-\mathrm{Cu}} / /[111]_{\alpha-\mathrm{Fe}}$ direction should be:

$\delta_{2}=\left|\frac{\sqrt{2} a_{\mathrm{Cu}}-\sqrt{3} a_{\alpha-\mathrm{Fe}}}{\sqrt{3} a_{\alpha-\mathrm{Fe}}}\right|=0.028$

where $a_{\mathrm{Cu}}$ and $a_{\alpha-\mathrm{Fe}}$ are the lattice constants of the copper precipitate and ferrite, which are $0.3615 \mathrm{~nm}$ and $0.2870 \mathrm{~nm}$, respectively. The specific interfacial energy caused by misfit dislocation is given as follows (Ref 18):

$\sigma=\frac{G b}{4 \pi(1-v)} f(\delta)$

where $\mathrm{G}$ is the shear modulus, $\mathrm{b}$ is the absolute value of the Burgers vector of the dislocation and $v$ is Poisson's ratio (Ref 18).

$f(\delta)=\delta\left[\frac{2}{1+\frac{1}{4 \delta^{2}}}-\ln (2 \delta)\right]$

$f\left(\delta_{1}\right)$ and $f\left(\delta_{2}\right)$ were found to be 0.2580 and 0.0825 , respectively. Since $f\left(\delta_{2}\right)$ is significantly smaller than $f\left(\delta_{1}\right)$, the shape coefficient $\eta$ of the copper-precipitated phase in ferrite is:

$$
\begin{aligned}
\eta & =\frac{\sigma_{2}}{\sigma_{1}}=\frac{b_{1} f\left(\delta_{1}\right)+b_{2} f\left(\delta_{2}\right)}{2 b_{2} f\left(\delta_{2}\right)}=\frac{\frac{2}{\sqrt{3}} a_{\mathrm{Cu}} f\left(\delta_{1}\right)+\frac{\sqrt{2} a_{\mathrm{Cu}}}{2} f\left(\delta_{2}\right)}{\sqrt{2} a_{\mathrm{Cu}} f\left(\delta_{2}\right)} \\
& =3.053
\end{aligned}
$$

The shape coefficient of the second phase was determined by its orientation relationship with the matrix. The morphology of the copper precipitate was determined based on the interfacial energy between the copper precipitate and the matrix.

The change in the specific interfacial energy with temperature mainly depended on the change in the elastic modulus of copper with the temperature. Its shear modulus at high temperature can be calculated as follows (Ref 18):

$$
\begin{aligned}
G(\mathrm{MPa}) & =46400 \times[1-(T-293) \times 0.00038] \\
& =51566-17.632 \mathrm{~T}
\end{aligned}
$$

where $T$ is the absolute temperature, $\mathrm{K}$.

The specific interfacial energy of the bottom surface, $\sigma_{1}$, and the side surface, $\sigma_{2}$, in the copper precipitate can be obtained as follows (Ref 18):

$$
\begin{aligned}
\sigma_{1} & =\frac{G b_{2}}{2 \pi(1-v)} f\left(\delta_{2}\right)=\frac{\sqrt{2} G a_{\mathrm{Cu}}}{4 \pi(1-v)} f\left(\delta_{2}\right) \\
& =0.2664-9.1 \times 10^{-5} \mathrm{~T}
\end{aligned}
$$

$$
\begin{aligned}
\sigma_{2} & =\frac{G b_{1}}{4 \pi(1-v)} f\left(\delta_{1}\right)+\frac{G b_{2}}{4 \pi(1-v)} f\left(\delta_{2}\right) \\
& =\frac{G}{4 \pi(1-v)} \cdot \frac{2}{\sqrt{3}} a_{\mathrm{Cu}} \cdot f\left(\delta_{1}\right)+\frac{G}{4 \pi(1-v)} \cdot \frac{\sqrt{2}}{2} a_{\mathrm{Cu}} f\left(\delta_{2}\right) \\
& =0.8147-0.2786 \times 10^{-3} \mathrm{~T}
\end{aligned}
$$

The average specific interfacial energy is:

$\bar{\sigma}=\frac{3}{\frac{1}{\sigma_{1}}+\frac{2}{\sigma_{2}}}=0.4832-0.1652 \times 10^{-3} \mathrm{~T}$

\subsection{Effect of Annealing Time on the Size of Copper-Precipitated Phases}

A short annealing time results in a precipitated phase that is too small. Thus, APT technology was used to observe the precipitated phase. The number density, $N_{\mathrm{v}}$, and the average equivalent radius, $R_{\mathrm{p}}$, of the precipitate were used for its characterization and analysis. $N_{\mathrm{v}}$ and $R_{\mathrm{p}}$ can be calculated as follows (Ref 21):

$N_{\mathrm{v}}=\frac{N_{\mathrm{P}} \zeta}{n_{\mathrm{a}} \Omega}$

$R_{\mathrm{P}}=\sqrt[3]{\frac{3 n_{\mathrm{p}} \Omega}{4 \pi \zeta}}$

where $N_{\mathrm{p}}$ is the number of copper precipitates detected in the analyzed volume; $\zeta$ is the detection reconstruction coefficient of APT, which is generally $0.6 ; n_{\mathrm{a}}$ is the total number of atoms collected in the analyzed volume; $\Omega$ is the average volume of the atom, which is $1.178 \times 10^{-2} \mathrm{~nm}^{3}$ for BCC Fe; $n_{\mathrm{p}}$ is the number of atoms in the copper precipitate; and $\pi(=3.14)$ is the circularity.

A continuous annealing experiment was conducted on a continuous annealing simulator for an annealing time of less than $2400 \mathrm{~s}$. Figure 2 shows the distribution of copper atoms in the tested steel aged at $800{ }^{\circ} \mathrm{C}$ for different times ( $\leq 60 \mathrm{~s}$ ). Figure 2(a) shows the distribution of copper atoms aged at $800{ }^{\circ} \mathrm{C}$ for $0 \mathrm{~s}$, i.e., it was only solution-treated at $970 \mathrm{C}$. The figure shows that copper atoms were uniformly distributed in the matrix, but the copper precipitate was not detected. This result suggests that the $\mathrm{Cu}$ atoms have been completely dissolved in the matrix after the solution treatment at $970{ }^{\circ} \mathrm{C}$ for $5 \mathrm{~min}$. Thus, solution annealing process is a reasonable choice. Figure 2(b) shows the distribution of copper atoms annealed at $800{ }^{\circ} \mathrm{C}$ for $10 \mathrm{~s}$ after solution treatment, in which 237 spherical nano-copper precipitates were detected with sizes within the range of $0.50-0.55 \mathrm{~nm}$. At this stage, the nanocopper precipitate is at its early stage of nucleation and the number density of the copper precipitate was calculated to be $4.8 \times 10^{23} \mathrm{~m}^{-3}$. Figure 2(c) shows the distribution of copper atoms annealed at $800 \mathrm{C}$ for $30 \mathrm{~s}$ after solution treatment, in which 8 spherical nano-copper precipitates were detected. The equivalent radius of the precipitated phase was between 0.45 and $7.5 \mathrm{~nm}$ with an average radius of $2.96 \mathrm{~nm}$, and the number density of the copper precipitate was calculated to be $1.7 \times 10^{22} \mathrm{~m}^{-3}$. During this period, the copper precipitate is in the growing and coarsening stage. Figure 2(d) shows the 


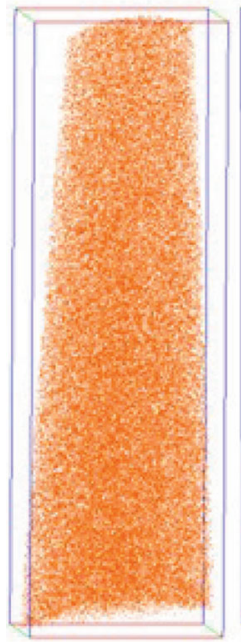

(a)

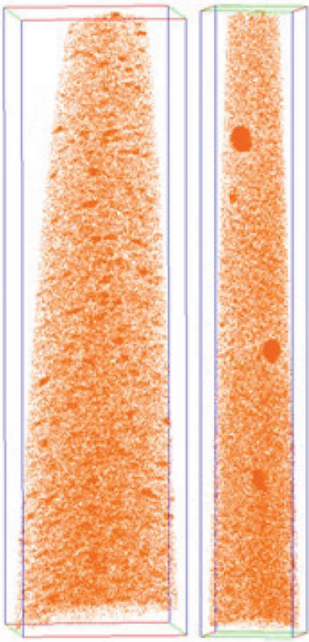

(b) (c)

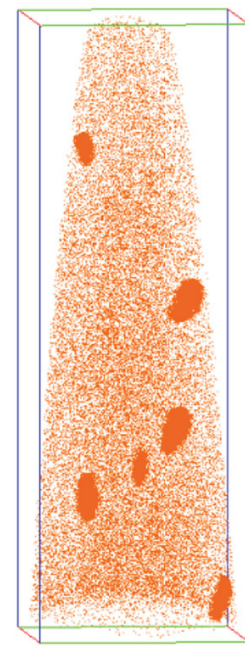

(d)
Fig. 2 Distribution of copper atoms in the tested steel samples aged at $800{ }^{\circ} \mathrm{C}$ for: (a) $0 \mathrm{~s}$, (b) $10 \mathrm{~s}$, (c) $30 \mathrm{~s}$ and (d) $60 \mathrm{~s}$. The analyzed 800 (a) $213 \times 65 \times 67 \mathrm{~nm}^{3}$ $408 \times 60 \times 62 \mathrm{~nm}^{3}$ $288 \times 74 \times 76 \mathrm{~nm}^{3}$
$258 \times 87 \times 89 \mathrm{~nm}^{3}$

distribution of copper atoms annealed at $800{ }^{\circ} \mathrm{C}$ for $60 \mathrm{~s}$ after solution treatment, in which 15 ellipsoidal nano-copper precipitates were detected. The equivalent radius of the precipitated phase was between 5.0 and $7.5 \mathrm{~nm}$, the average radius was $6.5 \mathrm{~nm}$, and the number density of the copper precipitate was calculated to be $1.0 \times 10^{22} \mathrm{~m}^{-3}$. Therefore, the size of the copper precipitate increased with the increase in the annealing time, whereas the number density decreased with the change in the shape from spherical to ellipsoidal.

Figure 3 shows the distribution of the copper precipitate at different continuous annealing times (180, 600 and $2400 \mathrm{~s})$. The number of copper precipitates decreased with the increase in the annealing time with a change in the morphology of copper precipitate from ellipsoidal to rod-shaped. Figure 3(a) shows a photograph of the copper precipitate annealed for $180 \mathrm{~s}$. The copper precipitate was ellipsoidal and uniformly dispersed with a size of $8.8 \pm 0.2 \mathrm{~nm}$. The number of copper precipitates was 160,69 per $100 \mu^{2}$. Figure 3(b) shows a photograph of the copper precipitate annealed for $600 \mathrm{~s}$. At this point, the copper precipitate was still ellipsoidal with an average size of $15.5 \pm 0.3 \mathrm{~nm}$, but with uneven distribution. The number of copper precipitates was 2205 per $100 \mu \mathrm{m}^{2}$. By extending the annealing time to $2400 \mathrm{~s}$, the large precipitated particles engulfed the small particles, and the average size of the copper precipitate continued to grow. The average size reached $28.7 \pm 1.1 \mathrm{~nm}$ with a few rod-shaped features. The number of the copper precipitates in this case was 822 per $100 \mu \mathrm{m}^{2}$ (Fig. 3c). The numbers and sizes of copper precipitates on different ferrite grains were quite different. This can be attributed to the different precipitation energy of copper on different crystal faces. Typically, copper precipitates on $\{110\}$.

Figure 4 shows the HRTEM and FFT images of the precipitated phase in the tested steel annealed for $2400 \mathrm{~s}$. The FFT image shows that the copper-precipitated phase had an FCC structure.

The samples were annealed in muffle furnace for more than 2400 s. Figure 5 shows the TEM images of the tested steel annealed for $3600,21,600$ and 36,000 s. Rod-shaped copper precipitates were obtained. The rod length increased and the number of precipitates decreased with the increase in the annealing time. At an annealing time of $3600 \mathrm{~s}$, the length and width of the rods were $250-300 \mathrm{~nm}$ and $60-70 \mathrm{~nm}$, respectively, and the shape coefficient of precipitates ranged from 3.5 to 5.0. The number of copper precipitates was 173 per $100 \mu \mathrm{m}^{2}$ (Fig. 5a). By extending the annealing time to $21,600 \mathrm{~s}$, the copper precipitate grows significantly, and the length and width of the rods were within the ranges of $420-470 \mathrm{~nm}$ and 75$85 \mathrm{~nm}$. The shape coefficient of precipitates ranged from 5.0 to 6.2. In addition, the number of copper-precipitated phases was reduced to 145 per $100 \mu^{2}$ (Fig. 5b). By extending the annealing time to $36,000 \mathrm{~s}$, the copper precipitate continued to grow, and the length and width of the rods were within the ranges of $600-650 \mathrm{~nm}$ and $70-80 \mathrm{~nm}$. The shape coefficient of precipitates was between 7.5 and 9.3. The number of copper precipitates was reduced to 131 per $100 \mu^{2}$ (Fig. 5c). After annealing for more than $21,600 \mathrm{~s}$, the number of precipitates was almost the same, but the width of precipitate decreased. Therefore, the growth in the size of the precipitated rods was due to the change of their shapes rather than the swallowing of other smaller precipitates.

The morphology of copper rich phase was determined by the interface energy between copper precipitation and ferrite matrix. The theoretical calculation 3.053 of the shape coefficient was based on the mismatch degree of semi-coherent interface. The TEM images showed that the shape coefficients of the copper precipitate annealed for $3600 \mathrm{~s}$ was the closest to the theoretical value. But the shape coefficient significantly increased with the increase in the annealing time, as shown in Fig. 5. This is because of that the theoretical calculation was based on the mismatch degree of semi-coherent interface, but the phase interface changed from semi-coherent interface to non-coherent interface during the growth of copper precipitates.

Due to the addition of high $\mathrm{Cr}$ content in the tested steel, the precipitation temperature range of copper precipitates in the steel increased. Therefore, the annealing temperature $\left(800^{\circ} \mathrm{C}\right)$ of copper precipitation in the tested steel was significantly higher than that in low-carbon steel $\left(500-600{ }^{\circ} \mathrm{C}\right)(\operatorname{Ref} 7-10)$. Consequently, the precipitation kinetics and morphology evolution process of the tested steel were significantly different from that of the low-carbon copper-bearing steel. Higher annealing temperature and higher copper content increased the growth rate and final size of copper precipitates in the tested steel, which provides conditions for obtaining copper precipitates with antibacterial properties.

\subsection{Antibacterial Properties}

Figure 6 shows the effect of antibacterial properties of the tested steel at different annealing times. With the increase in the annealing time, the number of colonies decreased significantly. Almost no colonies were detected after annealing for more than $3600 \mathrm{~s}$. This suggests that the annealing time has a significant effect on the antibacterial properties of the tested steel. Figure 7 shows the change of antibacterial rate of test steel with continuous annealing time. The antibacterial activity of the tested steel increased with the increase in the annealing time until it reached approximately $100 \%$. The antibacterial activity was over $99 \%$, and excellent antibacterial properties were obtained after the annealing time exceeded $3600 \mathrm{~s}$. As the antibacterial properties of the tested steel can be mainly 

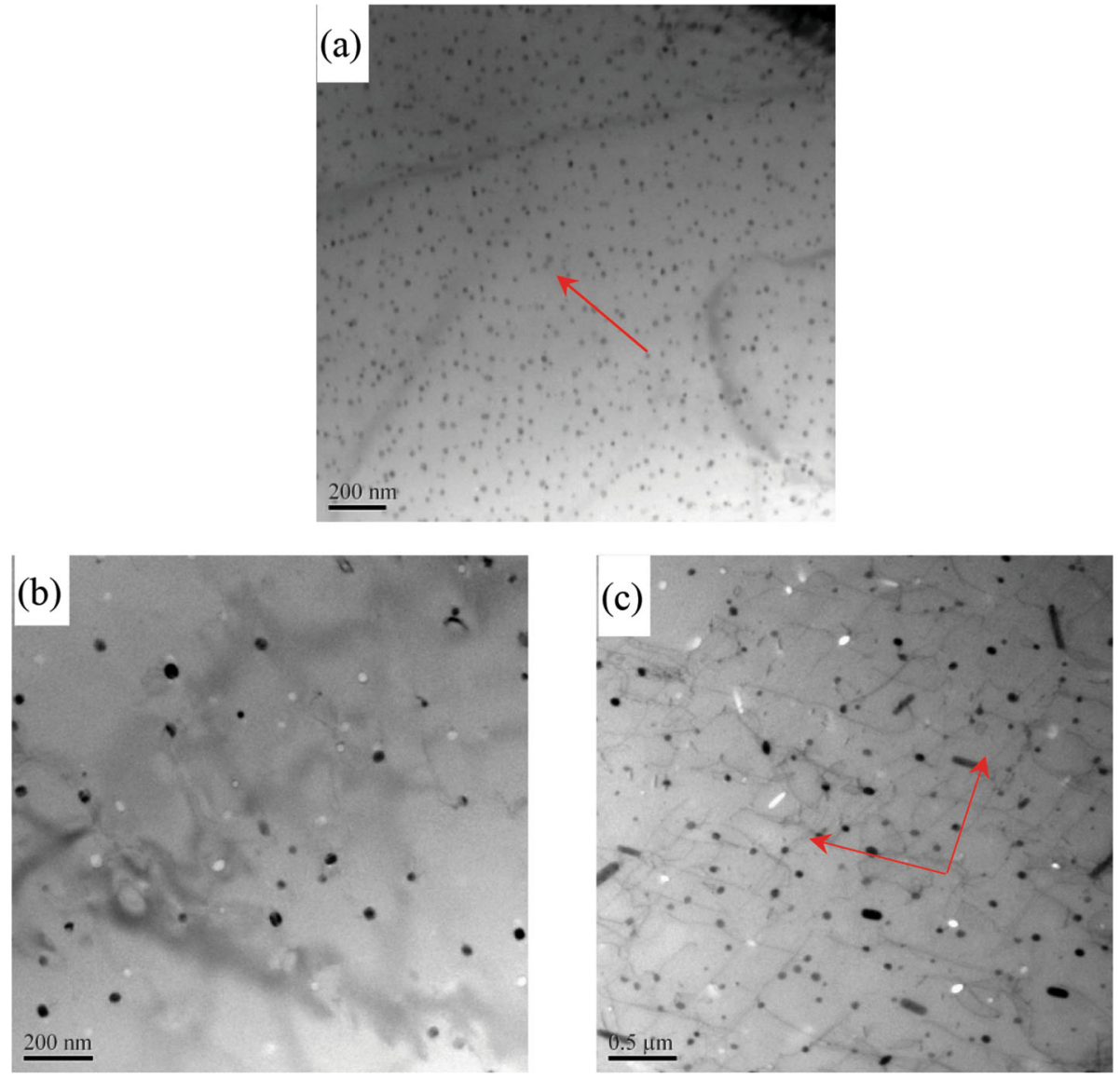

Fig. 3 TEM images of tested steel with different continuous annealing times (a) $180 \mathrm{~s}$ (b) $600 \mathrm{~s}$ (c) $2400 \mathrm{~s}$

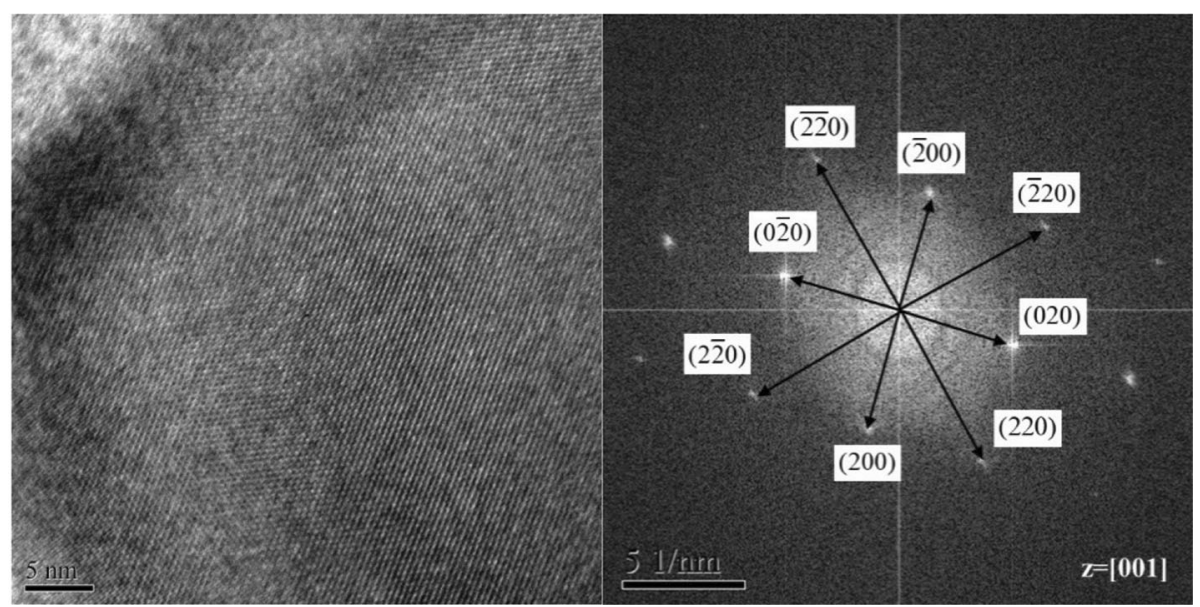

Fig. 4 Images of the tested steel annealed for 2400 s. (a) HRTEM image (b) FFT image

examined through the copper precipitate in contact with viruses and bacteria, a surface sphere equal in size to that of the rodshaped precipitates was proposed. The equivalent sphere size can be calculated as follows:

$D_{\mathrm{s}}=\sqrt{\frac{D_{0}^{2}}{2}+D_{0} L}$
The total area of the precipitate per $100 \mu \mathrm{m}^{2}$ of the sample was given as follows:

$S_{\mathrm{t}}=N \pi D_{\mathrm{s}}^{2}$

where $D_{\mathrm{s}}$ is the equivalent sphere size; $D_{0}$ is the bottom diameter of the rod-shaped precipitate; $L$ is the length of the rod-shaped precipitate; $S_{\mathrm{t}}$ is the total area of the precipitate on the area of $100 \mu \mathrm{m}^{2}$ of the sample; $\mathrm{N}$ is the number of 

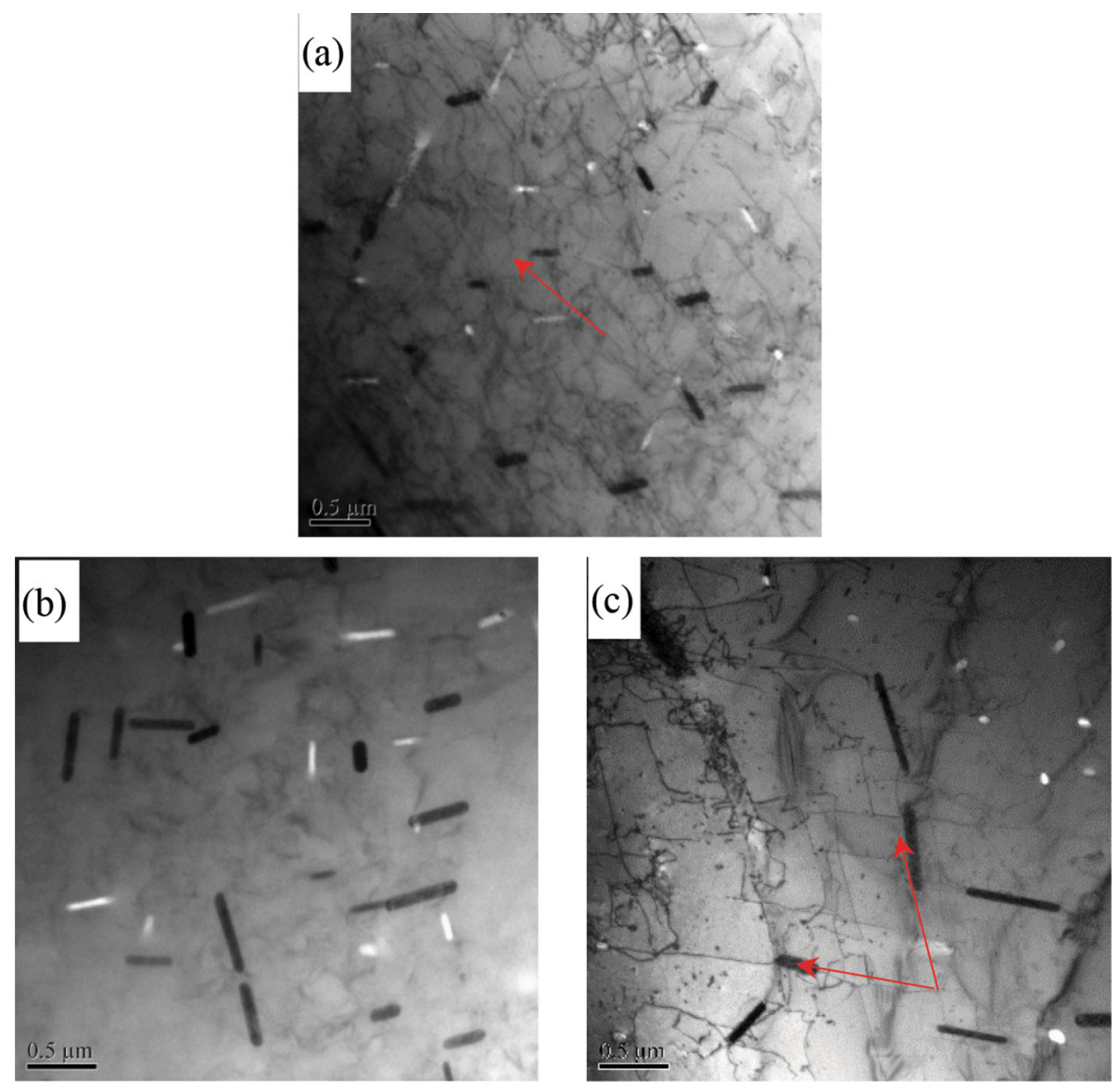

Fig. 5 TEM images of the tested steel with different annealing times in the furnace. (a) $3600 \mathrm{~s}$, (d) $21,600 \mathrm{~s}$ and (c) 36,000

precipitates per $100 \mu^{2}$; and $\pi$ is the circumference ratio, which is considered to be 3.14 .

Because of the low-resolution TEM and the very small size of the precipitate, the number of precipitates annealed for $60 \mathrm{~s}$, which were observed using TEM, is less than the actual number. By increasing the annealing time to more than $60 \mathrm{~s}$, the copper-precipitated phase nearly reached an equilibrium state, i.e., the precipitated volume remained basically unchanged. Figure 8 shows the size and the total area of the precipitate per $100 \mu^{2}$ at different annealing times. The size and area per $100 \mu^{2}$ showed a similar variation trend to that of the change in the antibacterial activity with time. With the increase in the annealing time, the average equivalent size of the precipitate continuously increased. When the annealing time reached $3600 \mathrm{~s}$, the average equivalent sphere diameter reached $141.2 \mathrm{~nm}$. The total area of the precipitate per $100 \mu \mathrm{m}^{2}$ decreased at first and then showed a continuous increasing trend. At the beginning, the precipitate grew up by merging between large particles and small ones, and its shape remained spherical or ellipsoidal. At a constant total volume, the total surface area of a sphere shape is the smallest among all shapes (spheres have larger diameters and smaller number). Therefore, the total area of precipitate decreased at the beginning, followed by a change in the precipitate shape from spherical or ellipsoidal to rod-shaped. Thus, the total surface area of the precipitate per unit continues increased with the change into the rod shape. At an annealing time of $3600 \mathrm{~s}$, the total area of the precipitate reached $10.83 \mu \mathrm{m}^{2}$ per $100 \mu \mathrm{m}^{2}$.
In previous studies (Ref 11-13), the ferritic stainless steel was mainly subjected to antibacterial heat treatment on the hotrolled plate before cold rolling, and the annealing time was about 2-6 h. Copper precipitates can dissolve during the cold rolling process, resulting in a decrease in the precipitate size, which is unfavorable to antibacterial properties. In the current test, the antibacterial heat treatment process was adjusted after cold rolling. Consequently, good antibacterial properties of the test steel were obtained only after annealing for $1 \mathrm{~h}$, which greatly saved the heat treatment time.

In addition, the mechanical properties, corrosion resistance and formability of the test steel were significantly better than the results of previous research. These properties will be discussed in a future work.

\subsection{Antibacterial Mechanism}

Figure 9 shows a schematic diagram illustrating the antibacterial action of the tested steel. Figure 9(a) shows a schematic diagram of the microstructure of the tested steel after solution treatment at $970{ }^{\circ} \mathrm{C}$ and dissolving of the copper atoms in the ferrite matrix. The antibacterial activity was the lowest at this stage because copper atoms cannot break through the passivation film to be in contact with the bacteria to play an antibacterial role.

Figure 9(b) shows a schematic diagram of the microstructure of the tested steel after a continuous annealing process, which resulted in copper precipitates mainly distributed on the ferrite matrix in granular form. Because the continuous 

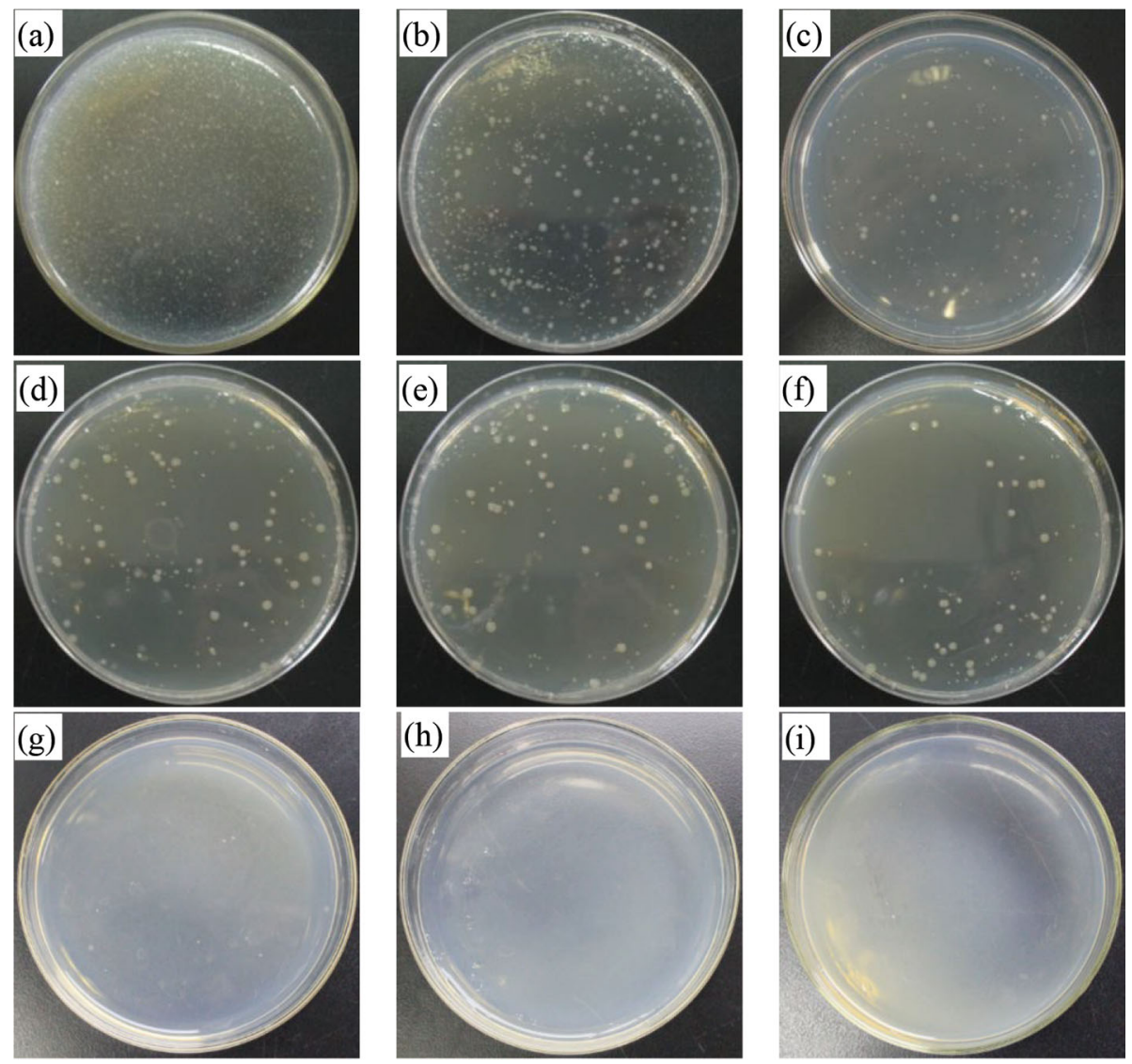

Fig. 6 Antibacterial properties of the tested samples: (a) Negative comparison diagram and after an annealing time of (b) $0 \mathrm{~s}$, (c) $60 \mathrm{~s}$, (d) $180 \mathrm{~s}$, (e) $600 \mathrm{~s}$, (f) $2400 \mathrm{~s}$, (g) $3600 \mathrm{~s}$, (h) $21,600 \mathrm{~s}$ and (i) $36,000 \mathrm{~s}$

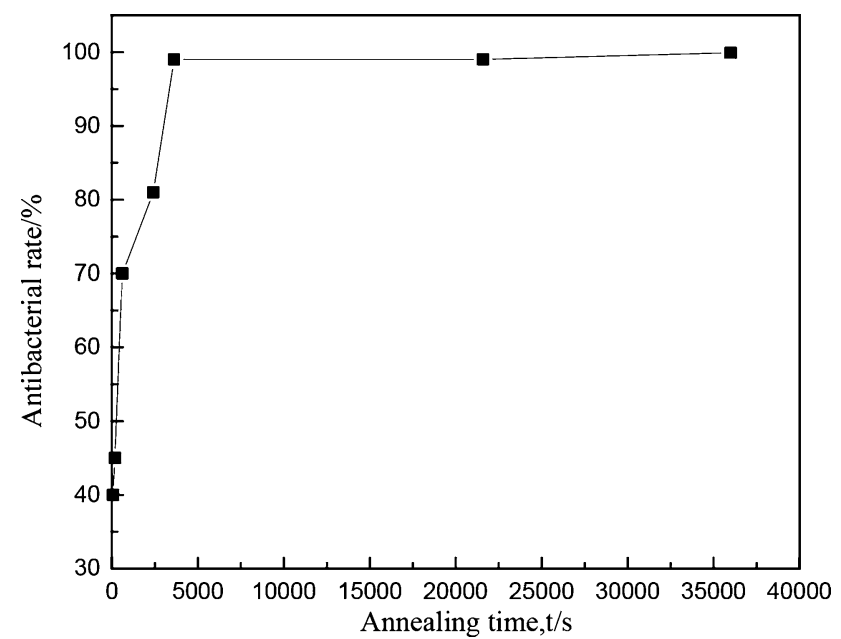

Fig. 7 Change in the antibacterial activity with the annealing time

annealing time was short and the heat preservation usually does not exceed $600 \mathrm{~s}$, the size of the spherical copper precipitate was less than $20 \mathrm{~nm}$, which is similar to the thickness of the passivation film (approximately 15-48 nm) (Ref 22). Therefore, the passivation film is hard to dissolve and can easily cover the copper precipitates. As a result, the area of copper precipitates which is in contact with the bacteria is small, leading to a low antibacterial activity.

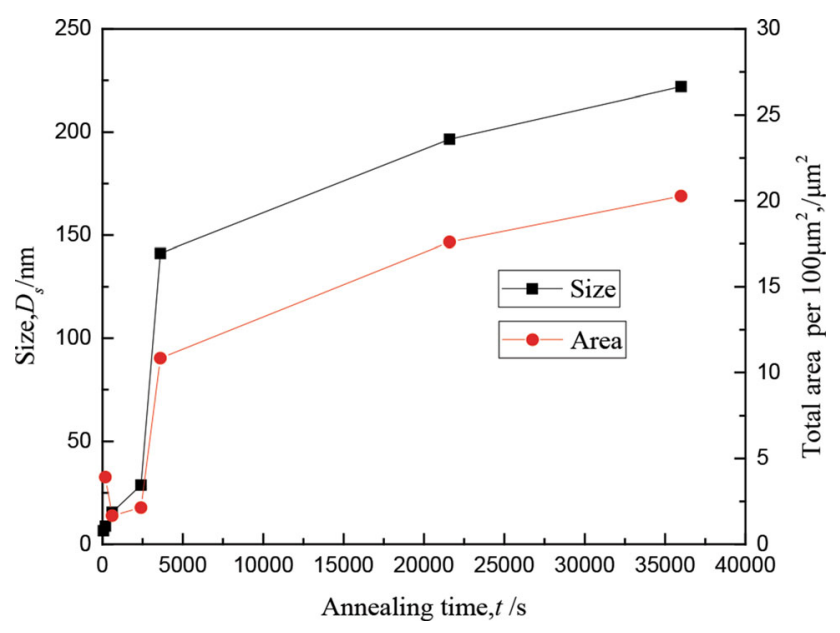

Fig. 8 Change in size and total area per $100 \mu \mathrm{m}^{2}$ of precipitate with the annealing time

Figure 9(c) shows the schematic diagram of the microstructure of the tested steel annealed in a furnace with rod-shaped copper precipitates mainly distributed on the ferrite matrix. Large copper precipitates were obtained after annealing for $3600 \mathrm{~s}$ with rod lengths within $250-300 \mathrm{~nm}$, which was much higher than the thickness of the passivation film. Thus, copper precipitates could directly penetrate the passivation film and 


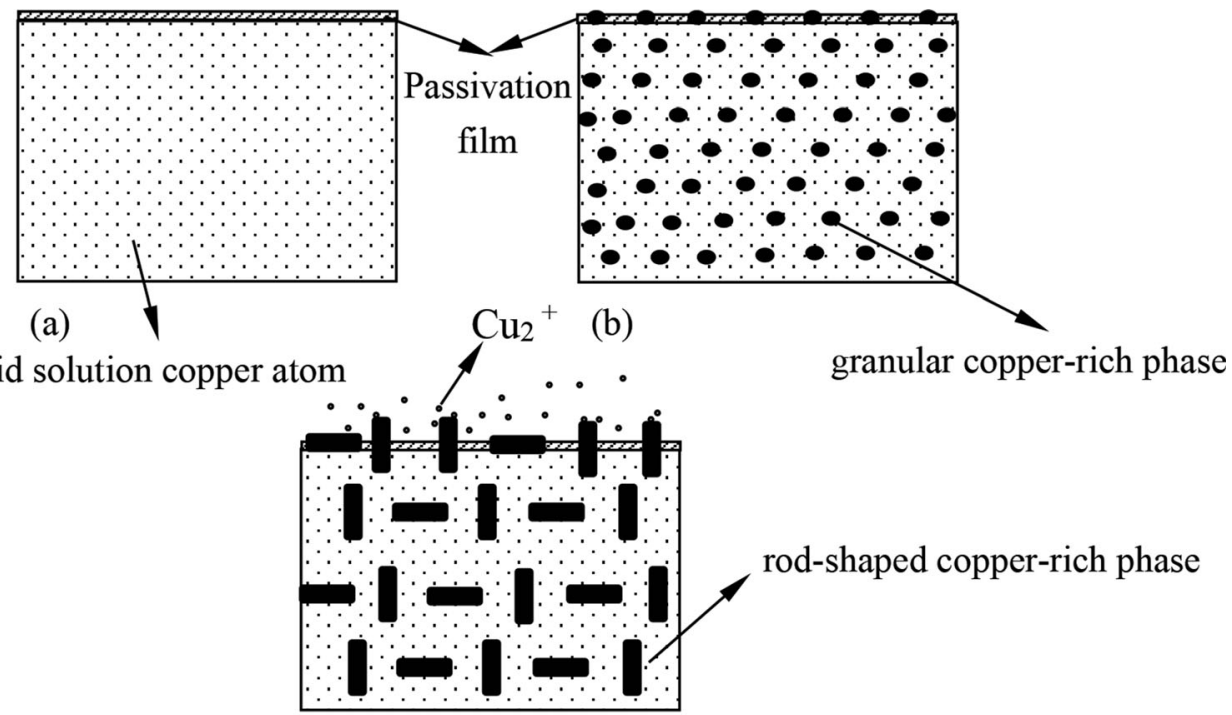

(c)

Fig. 9 Schematic diagram of the antibacterial action

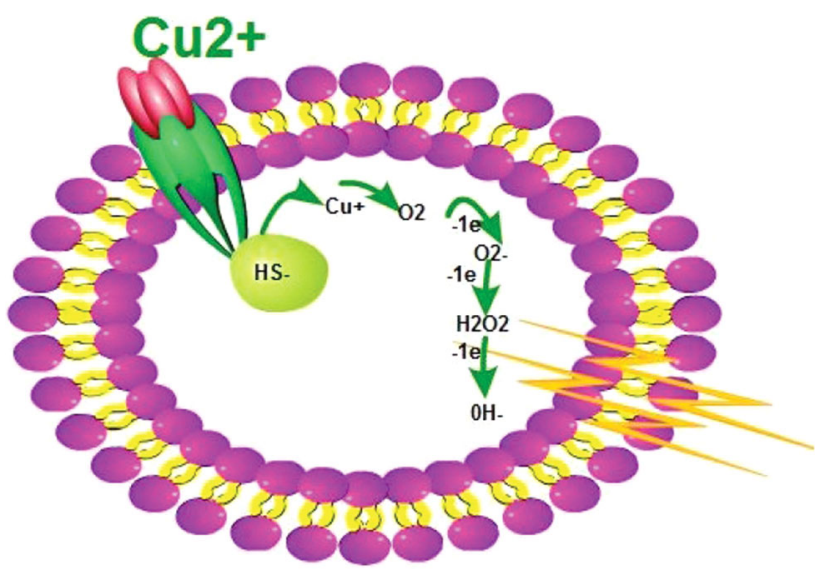

Fig. 10 Schematic diagram of $\mathrm{Cu}_{2}^{+}$ions killing bacterial cells

interact with the external bacteria. In order to kill most bacteria, copper precipitates in direct contact with the bacterial should reach a critical size and be sufficiently distributed in the ferrite matrix.

Copper ions $\left(\mathrm{Cu}^{2+}\right)$ are the form of copper that kills bacteria (Ref 14, 15). Figure 10 shows a schematic diagram of $\mathrm{Cu}^{2+}$ killing bacteria. When $\mathrm{Cu}^{2+}$ ions enter the cell, they undergo oxidation-reduction reactions with the thiolase in the microorganism. $\mathrm{Cu}^{2+}$ absorbs electrons and transforms into $\mathrm{Cu}^{+}$, while $\mathrm{O}_{2}$ converts into $\mathrm{O}_{2}{ }^{-}$. Then, $\mathrm{O}_{2}{ }^{-}$participates in a variety of reactions with bacteria, generating $\mathrm{H}_{2} \mathrm{O}_{2}$ and $-\mathrm{OH}$ free radicals that interact with the cell membrane, leading to the oxidation of unsaturated fatty acids and reductive enzymes on its surface. This leads to the rupture of the cell membrane and death of bacteria.

\section{Conclusions}

1. The size of the copper precipitate increases and the number density of copper precipitates in ferrite grain decreases with the increase in the aging time. The precipitated phase changes from the initial spherical to ellipsoidal particles, which finally convert into rod-shaped particles with the increase in the aspect ratio.

2. After annealing for more than $3,600 \mathrm{~s}$, the tested steel exhibited a superior antibacterial (killing up to $99 \%$ of the bacteria). The antibacterial performance is closely related to the size and the total area per unit area of the precipitate.

3. When the copper precipitate reached a certain size and the number of copper precipitates per unit area of the ferrite matrix exceeded a certain critical value, the copper precipitates could produce sufficient $\mathrm{Cu}^{2+}$ to kill most of the bacteria. Thus, they exhibited good antibacterial performance.

\section{References}

1. A.L. Casey, D. Adams, T.J. Karpanen et al., Role of Copper in Reducing Hospital Environment Contamination, J. Hosp. Infect., 2010, 74(1), p 72-77

2. S. Zhang, X.J. Liang, G.M. Gadd et al., Advanced Titanium DioxidePolytetrafluorethylene $\left(\mathrm{TiO}_{2}\right.$-PTFE) Nanocomposite Coatings on Stainless Steel Surfaces with Antibacterial and Anti-corrosion Properties, Appl. Surf. Sci., 2019, 490, p 231-241

3. S. Wang, C. Yang, L. Ren et al., Study on Antibacterial Performance of Cu-Bearing Cobalt-Based Alloy, Mater. Lett., 2014, 129, p 88-90

4. M. Bahmani-Oskooeea, S.H. Nedjada, A. Samadia et al., Cu-Bearing, Martensitic Stainless Steels for Applications in Biological Environments, Mater. Des., 2017, 130, p 442-451 
5. M. Hans, J.C. Támara, S. Mathews et al., Laser Cladding of Stainless Steel with a Copper-Silver Alloy to Generate Surfaces of High Antimicrobial Activity, Appl. Surf. Sci., 2014, 320, p 195-199

6. J.L. Zhao, Z.F. Zhai, D. Sun et al., Antibacterial Durability and Biocompatibility of Antibacterial-Passivated 316L Stainless Steel in Simulated Physiological Environment, Mater. Sci. Eng. C, 2019, 100, p 396-410

7. J. Yan, D. Huang, X. Zuo et al., Co-precipitation Kinetics, Microstructural Evolution and Interfacial Segregation in Multicomponent Nanoprecipitated Steels, Mater. Charact., 2019, 155, p 1-14

8. S.R. Goodman, S.S. Brenner, and J.R. Low, An FIM-atom probe study of the precipitate of copper from lron-1.4 at. pct copper. Part II: Atom probe analyses, Metall. Trans., 1973, 4(10), p 2371-2378

9. H. Schwich, D. Gorzen, B. Blinn et al., Characterization of the Precipitation Behavior and Resulting Mechanical Properties of CopperAlloyed Ferritic Steel, Mater. Sci. Eng. A, 2020, 772, p 1-9

10. P.J. Othen, M.L. Jenkins, and G.D.W. Smith, High-Resolution Electron Microscopy Studies of the Structure of $\mathrm{Cu}$ Precipitate in $\alpha$-Fe, Philos. Mag. A, 1994, 70(1), p 1-24

11. Z.X. Zhang, G. Lin, and Z. Xu, Precipitate of Epsilon Copper in Ferrite Antibacterial Stainless Steel, J. Mater. Sci. Technol., 2008, 24(5), p 775-780

12. S.H. Chen, M.Q. Lv, J.D. Zhang et al., Microstructure and Antibacterial Properties of Cu-Contained Antibacterial Stainless Steel, Acta Metall. Sin., 2004, 40(3), p 314-318

13. G. Lin, J.C. Shen, and R.M. Wang, Effect of $\mathrm{Cu}$ on the property of ferrite antibacterial stainless steel, Funct. Mater, 2011, 42(3), p 549551

14. O.V. Bakina, E.A. Glazkova, N.V. Svarovskaya et al., «Janus »-Like $\mathrm{Cu}-\mathrm{Fe}$ Bimetallic Nanoparticles with High Antibacterial Activity, Mater. Lett., 2019, 242, p 187-190
15. D. Markovic, C. Deeks, T. Nunney et al., Antibacterial activity of Cubased nanoparticles synthesized on the cotton fabrics modified with polycarboxylic acids, Carbohyd. Polym., 2018, 200, p 173-182

16. S. Wang, C. Yang, M. Shen et al., Effect of Aging on Antibacterial Performance of Cu-Bearing Martensitic Stainless Steel, Mater. Technol., 2014, 29(5), p 257-261

17. M. Bahmanioskooee, S.H. Nedjad, A. Samadi et al., Cu-Bearing, Martensitic Stainless Steels for Applications in Biological Environments, Mater. Des., 2017, 30, p 442-451

18. Q.L. Yong, The Secondary Phase in Steels, Vol 65, 70, 84, Metallurgical Industry Press, Beijing, 2006, p 231-234

19. Arthur.D. Pelton and Christopher.W. Bale, A Modified Interaction Parameter Formalism for Non-dilute Solutions, Metall. Trans. A, 1986, 17A, p 1211-1215

20. K. Ozbaysal and O.T. Inal, Age-Hardening Kinetics and AgeHardening Kinetics and Microstructure of PH 15-5 Stainless Steel After Laser Melting and Solution Treating, J. Mater. Sci., 1994, 29(6), p 1471-1480

21. M.K. Miller, Atom Probe Tomography: Analysis at the Atomic Level, Kluwer/Plenum, New York, 2000

22. W.M. Wang, X.B. Chen, and W.F. Zhao, Properties of Surface Passivating Film of Ferritic Stainless Steel 409L, Special Steel, 2009, 30(2), p 63-65

Publisher's Note Springer Nature remains neutral with regard to jurisdictional claims in published maps and institutional affiliations. 